\title{
ANALISIS PENGARUH BIAYA PRELIMINARIES TERHADAP PRODUKTIVITAS KARYAWAN PADA PROYEK-PROYEK PT. X
}

\author{
Clara Devina \\ Program Studi Magister Manajemen Universitas Tarumanagara \\ claradevina09@gmail.com \\ Eddy Herjanto \\ Program Studi Magister Manajemen Universitas Tarumanagara
}

Masuk : 30-11-2019, revisi : 21-12-2019 diterima untuk diterbitkan : 23-12-2019

\begin{abstract}
PT.X is a contractor that has productivity problem that is affected by the cost of preliminaries cost. Preliminaries cost for PT. X is divided into 5 parts consisting of employee costs, general costs, financial costs, preparation costs and equipment costs. Employee costs have the largest portion of the cost of other preliminaries. In this study, the authors intend to review the effect of cost preliminaries on productivity in PT. X. The results of the research show that employee costs are $43 \%$ of the total cost of preliminaries and $5 \%$ of the VOW value. Further research shows that the building type of the project, the number of employees, and employee salaries have a positive effect on the productivity value of a project. The strategy that companies can implement to increase productivity is to set project productivity targets of 480 million / person / month and $45 \mathrm{rp} / \mathrm{rp}$.
\end{abstract}

Keywords : Preliminaries Cost, Employee Cost, Productivity

Abstrak : Kontraktor PT X memiliki permasalahan produktivitas yang dipengaruhi oleh biaya preliminaries. Biaya preliminaries PT. X dibagi menjadi 5 bagian yang terdiri dari biaya karyawan, biaya umum, biaya keuangan, biaya persiapan dan biaya peralatan. Biaya karyawan memiliki porsi paling besar diantara biaya preliminaries lainnya. Pada penelitian ini, penulis bermaksud untuk meninjau pengaruh biaya preliminaries terhadap produktivitas di proyekproyek PT. X. Hasil penelitian menunjukan biaya karyawan sebesar $43 \%$ dari total biaya preliminaries dan sebesar 5\% dari nilai VOW. Penelitian selanjutnya menunjukan bahwa jenis bangunan proyek, jumlah karyawan, dan gaji karyawan berpengaruh positif terhadap nilai produktivitas suatu proyek. Strategi yang dapat perusahaan terapkan untuk meningkatkan produktivitas yaitu dengan menetapkan target produktivitas proyek yaitu sebesar 480 juta/orang/bulan dan $45 \mathrm{rp} / \mathrm{rp}$.

Kata kunci : Biaya Preliminaries, Biaya Karyawan, Produktivitas.

\section{PENDAHULUAN}

Proyek adalah suatu rangkaian kegiatan yang dikerjakan dalam waktu terbatas menggunakan sumber daya tertentu dengan harapan untuk memperoleh hasil yang terbaik pada waktu yang akan datang. Dalam suatu proyek konstruksi, ada tiga elemen utama yang harus ditentukan dan terus diamati di dalam merencanakan suatu proyek. Hubungan antar elemen ini disebut "tiga batasan" yang terdiri dari waktu, biaya dan kualitas. Disini, produktivitas pekerja adalah kunci konsep menengah yang memiliki potensial untuk mempengaruhi semua elemen dan harus diperhitungkan dalam memahami kemungkinan interaksi diantara elemen-elemen tersebut.

Terdapat pembagian biaya pada proyek konstruksi, yaitu biaya langsung dan biaya tidak langsung (AACE, 1992). Biaya langsung (direct cost) merupakan semua biaya yang terkait 
langsung dengan volume pekerjaan yang meliputi biaya material, biaya upah buruh/mandor/tukang, dan biaya peralatan untuk pelaksanaan pekerjaan. Sedangkan biaya tidak langsung (preliminaries) adalah sebuah biaya pendukung dalam sebuah proyek konstruksi yang tidak menghasilkan secara fisik sebagai suatu bangunan.

Selain kegiatan-kegiatan yang kurang efektif diatas yang menyebabkan hambatan produktivitas, masih ada faktor lain yang menjadi pengaruh dalam produktivitas tenaga kerja. Faktor tersebut antara lain nilai produksi, durasi proyek, gaji karyawan, dan jumlah karyawan.

PT.X merupakan sebuah perusahaan konstruksi swasta di Indonesia yang berfokus pada bangunan tinggi / high rise building seperti perkantoran, apartemen, hotel, dll. Pada pelaksanaannya, sering kali proyek-proyek pada PT.X mengalami keterlambatan / delay dari yang sudah di rencanakan. Sehingga menyebabkan membengkaknya biaya preliminaries/ biaya tidak langsung. Pada biaya prelimianries/ biaya tidak langsung, biaya karyawan merupakan biaya terbesar diantara biaya preliminaries lainnya. Pada penelitian ini, biaya karyawan akan diteliti hubungannya dengan produktivitas karyawan.

\section{TINJAUAN KEPUSTAKAAN}

Filosofi tentang produktivitas sudah ada sejak awal peradaban manusia karena makna produktivitas adalah keinginan (the will) dan upaya (effort) manusia untuk selalu meningkatkan kualitas kehidupan dan penghidupan di segala bidang. Produktivitas adalah bagaimana menghasilkan atau meningkatkan hasil barang danjasa setinggi mungkin dengan memanfaatkan sumber daya secara efisien. Oleh karenaitu, produktivitas sering diartikan sebagai rasio antara keluaran dan masukan dalamsatuan tertentu (Harry.1999).

Adrian (1987) mengklasifikasikan faktor-faktor yang menyebabkan rendahnya produktivitas yaitu faktor industri konstruksi, faktor tenaga kerja, dan faktor manajemen. Faktor industri konstruksi adalah karakteristik industri konstruksi, seperti keunikan konstruksi proyek, perbedaan lokasi, dan cuaca yang tidak menentu.

Untuk mengetahui produktivitas tenaga kerja dalam masing-masing proyek objek penelitian, maka dilakukan perhitungan durasi pekerjaan dimana dianggap durasi pekerjaan tersebut mempengaruhi produktivitas tenaga kerja yang tersedia pada pelaksanaan proyek tersebut. Dalam penelitian tersebut, produktivitas tenaga kerja dihitung dengan rumusan sebagai berikut :

\section{Produktivitas $=($ Volume pekerjaan $) /($ Durasi pekerjaan $)$}

Volume pekerjaan pada persamaan di atas merupakan nilai VOW (Value of Work) sedangkan durasi pekerjaan merupakan durasi dari awal proyek sampai dengan batas waktu penelitian ini.

Oleh karena itu, nilai produktivitas tenaga kerja pada dasarnya dapat didefinisikan sebagai durasi hari yang diperlukan untuk menyelesaikan suatu kegiatan. Produktivitas juga diartikan sebagai tingkatan efisiensi dalam memproduksi barang atau jasa. L. Greenberg mendefinisikan produktivitas sebagai perbandingan antara totalitas pengeluaran pada waktu terterntu dibagi dengan totalitas masukan selama periode tersebut.

Menurut Kaming dalam Wulfram I Ervianto (2005) factor yang mempengaruhi produktivitas proyek diklasifikasikan menjadi empat kategori utama, salah satunya adalah manajemen tenaga kerja. Menurut Husen Abrar (2010), kuantittas atau jumlah tenaga kerja yang digunakan dalam suatu proyek mempengaruhi produktivitas proyek tersebut.

Menurut Kaming dalam Wulfram I Ervianto (2005) faktor yang mempengaruhi produktivitas proyek diklasifikasikan menjadi empat kategori utama, salah satunya adalah tingkat upah kerja atau gaji karyawan.

Selama berlangsungnya pekerjaan harus diukur hasil-hasil yang dicapai untuk dibandingkan dengan rencana semula. Obyek pengawasan ditujukan pada pemenuhan persyaratan minimal segenap sumber daya yang dikerahkan agar proses kontruksi secara teknis dapat berlangsung baik. Upaya mengevaluasi hasil pekerjaan untuk mengetahui penyebab 
penyimpangan terhadap estimasi semula. Pemantauan (monitoring) berarti melakukan observasi dan pengujuian pada tiap interval tertentu untuk memeriksa kinerja maupun dampak sampingan yang tidak diharapkan (Istimawan, 1996 :423).

Karena dalam rangka mengajukan tender, produktivitas tenaga kerja akan besar pengaruhnya terhadap total biaya proyek, minimal pada aspek jumlah tenaga kerja dan fasilitas yang diperlukan. Salah satu pendekatan untuk mencoba mengukur hasil guna tenaga kerja adalah dengan memakai parameter indeks produktivitas (Iman Soeharto, 1995 :162)

\section{METODOLOGI PENELITIAN}

Penelitian kuantitatif adalah suatu proses menemukan pengetahuan yang menggunakan data berupa angka sebagai alat menganalisis keterangan mengenai apa yang ingin diketahui (Kasiram (2008: 149) dalam bukunya Metodologi Penelitian Kualitatif dan Kuantitatif).

Penelitian produktivitas ini dilakukan dengan metode analisis. Data-data diperoleh penulis dengan cara melakukan kontak langsung dengan pihak-pihak yang terkait, yaitu officer yang memiliki tugas untuk mengontrol biaya preliminaries dan produktivitas di PT X. Data-data yang diperoleh dalam bentuk soft copy berupa file dalam format Microsoft Office.

\section{Data dari Proyek yang telah selesai :}

a. Data Biaya Karyawan

Biaya karyawan yang digunakan adalah saat realisasi proyek sampai dengan Desember 2018. Terdapat data jumlah karyawan dan gaji karyawan.

\section{b. Data Nilai Kontrak}

Data nilai kontrak yang digunakan adalah nilai kontrak sampai dengan Desember 2018.

\section{c. Data Durasi Proyek}

Data durasi proyek dari awal proyek sampai dengan akhir proyek.

\section{Populasi dan Sampel \\ Populasi}

Populasi dalam penelitian ini adalah 36 proyek yang telah selesai dibangun sampai dengan Desember 2018.

\section{Sampel}

Karena jumlah populasi pada penelitian ini tidak terlalu banyak, penulis mengambil seluruh populasi menjadi sampel (sample jenuh) yang berjumlah 36 proyek.

\section{Metode Analisis}

\section{Statistical Product and Service Solution (SPSS 23)}

Program SPSS (Statistical Product and Service Solution) adalah software untuk mengolah data statistik secara mudah sedangkan 23 adalah versi rilisnya. Program ini digunakan penulis untuk mengolah data penelitian dengan metode regresi berganda. Hasil yang disajikan oleh program ini sangat detail dan informatif, sehingga memudahkan penulis dalam menganalisis data sesuai tujuan penelitian.

\section{Metode Statitiska}

\section{Uji Normalitas}

Terdapat beberapa metode untuk uji normalitas, metode yang digunakan pada uji normalitas pada penelitian ini adalah Chi-Square. Metode Chi-Square menggunakan pendekatan penjumlahan penyimpangan data observasi tiap kelas dengan nilai yang diharapkan. Syarat untuk menggunakan metode Chi-Square adalah data tersusun dengan dikelompokkan dalam tabel distribusi frekuensi. 


\section{Statistika Regresi}

Regresi adalah kajian terhadap ketergantungan satu variabel, yaitu variabel tergantung terhadap satu atau lebih variabel lainnya atau yang disebut sebagai variabel - variabel eksplanatori dengan tujuan untuk membuat estimasi dan / atau memprediksi rata - rata populasi atau nilai rata - rata varibael tergantung dalam kaitannya dengan nilai- nilai yang sudah diketahui dari variabel eksplanatorinya. (Gujarati, 2009)

\section{ANALISIS DAN PEMBAHASAN}

Pemodelan Produktivitas terhadap Jenis Bangunan Proyek

Tabel 4.1 Koefisien dan Kolinieritas Statistik

\begin{tabular}{|c|c|c|c|c|c|c|c|c|c|c|}
\hline \multirow[b]{2}{*}{ Model } & \multicolumn{2}{|c|}{$\begin{array}{c}\text { Unstandardized } \\
\text { Coefficients }\end{array}$} & \multirow{2}{*}{$\begin{array}{c}\text { Standardized } \\
\text { Coefficients } \\
\text { Beta }\end{array}$} & \multirow[b]{2}{*}{$\mathrm{t}$} & \multirow[b]{2}{*}{ Sig. } & \multicolumn{3}{|c|}{ Correlations } & \multicolumn{2}{|c|}{$\begin{array}{c}\text { Collinearity } \\
\text { Statistics }\end{array}$} \\
\hline & $\mathrm{B}$ & Std. Error & & & & $\begin{array}{l}\text { Zero- } \\
\text { order }\end{array}$ & Partial & Part & Tolerance & VIF \\
\hline 1 (Constant) & 318157.996 & 115878.700 & & 2.746 & .010 & & & & & \\
\hline Durasi & 34373.722 & 5331.240 & .742 & 6.448 & .000 & .742 & .742 & .742 & 1.000 & 1.000 \\
\hline
\end{tabular}

a. Dependent Variable: Produktivitas

Pada kolom unstandardized coefficients didapatkan nilai konstanta dan koefisien nilai produksi yang dijadikan sebagai pemodelan nilai produktivitas terhadap jenis bangunan proyek, berikut adalah persamaan regresi yang didapat:

$$
\mathrm{Y}=-\mathrm{Rp} .318 .157 .996 .000+34.373,722 \mathrm{X}
$$

Keterangan:

Y : Durasi proyek

$\mathrm{X}$ : Nilai Produksi

\section{Pemodelan Produktivitas terhadap Jumlah Karyawan}

Tabel 4.2 Koefisien dan Kolinieritas Statistik

\begin{tabular}{|c|c|c|c|c|c|c|c|c|c|c|}
\hline \multirow[b]{2}{*}{ Model } & \multicolumn{2}{|c|}{$\begin{array}{c}\text { Unstandardized } \\
\text { Coefficients }\end{array}$} & \multirow{2}{*}{$\begin{array}{c}\begin{array}{c}\text { Standardized } \\
\text { Coefficients }\end{array} \\
\text { Beta } \\
\end{array}$} & & \multirow[b]{2}{*}{ Sig. } & \multicolumn{3}{|c|}{ Correlations } & \multicolumn{2}{|c|}{$\begin{array}{c}\text { Collinearity } \\
\text { Statistics }\end{array}$} \\
\hline & $\mathrm{B}$ & Std. Error & & & & \begin{tabular}{|l|} 
Zero- \\
order
\end{tabular} & Partial & Part & Tolerance & VIF \\
\hline 1 (Constant) & 40013.567 & 39475.910 & & -1.014 & .318 & & & & & \\
\hline ManMonth & 362.843 & 23.898 & .934 & 15.183 & .000 & .934 & .934 & .934 & 1.000 & 1.000 \\
\hline
\end{tabular}

a. Dependent Variable: Produktivitas

Tabel 4.2 memberikan persamaan yang dijadikan pemodelan. Pada kolom unstandardized coefficients didapatkan nilai konstanta dan koefisien nilai produksi yang dijadikan sebagai pemodelan produktivitas terhadap jumlah karyawan, berikut adalah persamaan regresi yang didapat:

$$
Y=- \text { Rp. } 40.013 .567+362.843 X
$$

Keterangan:

Y : Jumlah Karyawan

$\mathrm{X} \quad$ : Nilai Produksi 


\section{Pemodelan Produktivitas terhadap Gaji Karyawan}

Tabel 4.3 Koefisien dan Kolinieritas Statistik

\begin{tabular}{|c|c|c|c|c|c|c|c|c|c|c|}
\hline \multirow[b]{2}{*}{ Model } & \multicolumn{2}{|c|}{$\begin{array}{c}\text { Unstandardized } \\
\text { Coefficients } \\
\end{array}$} & \multirow{2}{*}{$\begin{array}{c}\begin{array}{c}\text { Standardized } \\
\text { Coefficients }\end{array} \\
\text { Beta } \\
\end{array}$} & \multirow[b]{2}{*}{$\mathrm{t}$} & \multirow[b]{2}{*}{ Sig. } & \multicolumn{3}{|c|}{ Correlations } & \multicolumn{2}{|c|}{$\begin{array}{c}\text { Collinearity } \\
\text { Statistics }\end{array}$} \\
\hline & B & Std. Error & & & & $\begin{array}{l}\text { Zero- } \\
\text { order }\end{array}$ & Partial & Part & Tolerance & VIF \\
\hline 1 (Constant) & $\begin{array}{r}- \\
53812.107\end{array}$ & 39579.250 & & -1.360 & .183 & & & & & \\
\hline Gaji & 56.755 & 3.692 & .935 & 15.374 & .000 & .935 & .935 & .935 & 1.000 & 1.000 \\
\hline
\end{tabular}

a. Dependent Variable: Produksi

Tabel 4.3 memberikan persamaan yang dijadikan pemodelan. Pada kolom unstandardized coefficients didapatkan nilai konstanta dan koefisien nilai produksi yang dijadikan sebagai pemodelan nilai produktivitas terhadap gaji karyawan, berikut adalah persamaan regresi yang didapat:

$$
\mathrm{Y}=-\mathrm{Rp} .53 .812 .107+56.755 \mathrm{X}
$$

Keterangan:

Y : Gaji Karyawan

$\mathrm{X} \quad$ : Nilai Produksi

\section{KESIMPULAN DAN SARAN} berikut:

Berdasarkan hasil penelitian yang dilakukan maka dapat ditarik kesimpulan sebagai

1. Jenis bangunan proyek mempengaruhi produktivitas karyawan. Perbedaan jenis bangunan pada setiap proyek menyebabkan perbedaan angka produktivitas. Karena setiap proyek memiliki karakteristik yang berbeda-beda.

2. Jumlah karyawan mempengaruhi produktivitas karyawan. Perbedaan jenis proyek mempengaruhi jumlah karyawan pada proyek.

3. Gaji karyawan mempengaruhi produktivitas karyawan. Perbedaan jenis proyek mempengaruhi komposisi karyawan pada proyek.

Berdasarkan hasil penelitian yang dilakukan maka saran yang dapat diberikan penulis, yaitu:

1. Dari segi corporate terdapat 2 ukuran yang dapat dijalankan oleh perusahaan. Yaitu

a. Nilai produksi IDR/bulan/jumlah karyawan $=480$ juta/orang/bulan

b. Nilai Produksi VOW IDR/ nilai karyawan IDR $=45 \mathrm{rp} / \mathrm{rp}$

2. Dari target yang sudah ditetapkan, maka dapat ditentukan strategic initiatives yang dapat dijalankan oleh perusahaan agar target tersebut dapat tercapai.

a. Meningkatkan perencanaan dan akurasi eksekusi pada proyek. Termasuk perencanaan pada jumlah karyawan dan gaji karyawan.

b. Meningkatkan jumlah sosialisasi teknologi / alat baru penunjang produktivitas karyawan.

c. Menyiapkan kemampuan engineering perusahaan dalam melaksanakan teknologi baru yang dapat meningkatkan produksi VOW.

3. Dari segi proyek terdapat 3 ukuran yang dapat dijalankan oleh proyek. Yaitu:

a. Nilai produksi IDR / bulan / jumlah karyawan $=480$ juta / bulan / orang

b. Nilai VOW / nilai karyawan $=45 \mathrm{rp} / \mathrm{rp}$

c. Implementasi inovasi / teknologi / alat baru penunjang produktivitas 
4. Dari target yang sudah ditetapkan, maka dapat ditentukan strategic initiatives yang dapat dijalankan oleh proyek agar target tersebut dapat tercapai.

a. Schedule proyek ahead / lebih cepat dari perencanaan.

b. Schedule jumlah karyawan dan gaji karyawan sama dengan perencanaan.

\section{DAFTAR PUSTAKA}

Handoko, Hani.T. (1984). Dasar-dasar Manajemen Produksi dan Operasi. Yogyakarta: BPFE

Kaming, P.F., Olomaiye, P.O., Holt, G.D., and Harries, F.C. (1997). "Factors Influencing Craftsmen's Productivity in Indonesia." International Journal of Project Management. Vol. 15, No. 1, 21-30.

Oglesby, C. H., Parker H.W. and Howell G.A. (1989). Productivity Improvement in Construction, McGraw-Hill.

Levin, Richard. I., and Rubin, David. S. (1998). Statistic for Management. United States of America: Prentice Hall

Oglesby. Dkk. 1989. Productivity Improvement In construction. McGraw - Hill Book Company : New York

Puspantopro, Benny. 1984. Konstruksi Bangunan. Jakarta : Gramedia.

Raviano, R Putra. 1992. Dasar - dasar Produktivitas. Jakarta : Karunika UT.

Sinungan, Muchdarsyah. 1997. Produktivitas, Apa dan Bagaimana. Jakarta : Bumi Aksara.

Soeharto, Imam. 1989. Menejemen Proyek : Dari Konseptual Sampai Oprasional. Jakarta : Erlangga. 